Research Article

\title{
The Influence of Trust on Crowd Logistics Enterprise's Operational Performance: A SEM-PLS Model
}

\author{
Hou Bin, ${ }^{1}$ Xue Yu, ${ }^{1}$ Yanling Zheng $\mathbb{D}^{2}{ }^{2}$ Yaohui Jiang, ${ }^{3}$ and Huanfang Wang ${ }^{1}$ \\ ${ }^{1}$ School of Business, Hunan University of Technology, Zhuzhou 412000, China \\ ${ }^{2}$ School of Management, Guilin University of Aerospace Technology, Guilin 541004, China \\ ${ }^{3}$ Business School, Shanghai University of Finance and Economics, Shanghai 200000, China \\ Correspondence should be addressed to Yanling Zheng; zyl@guat.edu.cn
}

Received 10 November 2021; Revised 25 November 2021; Accepted 1 December 2021; Published 17 December 2021

Academic Editor: Tongguang $\mathrm{Ni}$

Copyright (c) 2021 Hou Bin et al. This is an open access article distributed under the Creative Commons Attribution License, which permits unrestricted use, distribution, and reproduction in any medium, provided the original work is properly cited.

\begin{abstract}
With the development of information communication and satellite positioning, crowd logistics has gradually emerged as a popular urban distribution mode for logistics enterprises. Trust and synergy between the crowd workers and the crowd logistics enterprises have become key issues in urban logistics development. Based on commitment-trust theory and logistics synergy, this paper developed a theoretical model exploring ability trust, goodwill trust, logistics synergy, and crowd logistics operational performance. We used SmartPLS software to analyze the questionnaire survey from 50 senior managers in crowd logistics enterprises. The results show that ability trust has a significant positive impact on logistics synergy and operational performance. Logistics synergy was also found to increase the operational performance of crowd logistics enterprises and plays a mediating role in the impact of ability trust and goodwill trust on operational performance. We recommend that logistics enterprises evaluate their crowd workers' service abilities, promote trust relationships with them, strengthen the construction of crowd logistics mechanisms, and invest in crowd worker training and development.
\end{abstract}

\section{Introduction}

With the rise of the sharing economy, many new business forms have developed, including crowd logistics. Crowdsourcing is a collaborative operation that integrates external knowledge and resources with enterprise technology to generate innovation [1]. With the crowdsourcing mode, logistics enterprises can gather scattered and idle external resources [2] and outsource the distribution activities originally performed by their employees to non-fixed social groups through the internet platform [3]. Given logistical difficulties, such as shortages in terminal logistics distribution resources and large fluctuations in market demand, crowd logistics provides an innovative solution to ameliorate delivery efficiency and reduce operating costs [4]. Dada Express, for example, has more than 4 million registered crowd workers on the platform, covering more than 1,400 cities across the country with over 40 million active users [5]. The emergence of crowd logistics has effectively solved the issues of delivery warehouse bursting, difficulties in resource integration, and low-efficiency distribution, resulting in huge economic benefits to enterprises [6]. Meanwhile, advances in information and communication technology, satellite location, and navigation [6] have opened up further opportunities for the crowd logistics development. The platformization and intellectualization of crowdsourcing logistics also match the industry 4.0 era's development needs. As a result, crowdsourcing logistics is becoming increasingly popular in urban distribution.

From the perspective of resources, enterprises regard crowd workers as external resources, achieving resource integration through crowdsourcing [7]. When internal and external synergies are transformed into synergies of enterprises, enterprise performance can be elevated [8]. However, while crowd logistics can promote cost reduction and increase efficiency, problems such as consumer information leakage and mishandled or damaged parcels occasionally happen. Some major reasons for these problems include immature development of the practice, weak stickiness of the public, and non-employment of crowd workers [6]. In 
particular, trust issues between the enterprise and crowd workers are prominent $[6,9]$, affecting enterprises' synergy efficiency, service quality, and operational performance.

At present, studies on the impact of trust in the operational performance of logistics enterprises have mostly focused on the integration of third-party logistics and related fields (e.g., Zaheer et al., 1998 [10]; Luo et al., 2015 [11]; and Wang et al., 2009 [12]), largely overlooking trust issues at the crowdsourcing level [9]. Some studies have discussed the impact of trust on crowdsourcing performance from the perspective of the overall crowdsourcing environment (e.g., Yao et al., 2019 [7] and Ye and Kankanhalli, 2017 [9]), and very few have explored the impact of trust on operational performance particularly in crowd logistics. The trust issue between crowd workers and logistics companies has produced a slew of social problems. There is also a study on this topic gap. Therefore, our study motivation is to make up for this gap in the literature and provide practical implications for crowd logistics participants. The questions to be tackled in this paper are: how does logistics synergy and trust between crowd workers and crowdsourcers impact the operational performance of the crowd logistics enterprise? On a micro level, resolving this issue aids in enhancing the synergistic efficiency of the crowd worker and the enterprise; on a macro level, it promotes the long-term development of urban logistics.

This study addresses some of these research oversights. To ensure the depth of analysis, this study focuses mainly on physical crowd logistics. By applying theories in commitment, trust, and logistics synergy, a research model was developed exploring the impact of trust and the mediating role of logistics synergy on enterprises' operational performance. The main contribution of our research is the construction of a theoretical model of the relationship between trust and crowd logistics enterprise's operational performance. The results of this study can help promote cooperation between the enterprises and crowd workers, improve operational performance, and enhance the service level of crowd workers. Customers, meanwhile, can profit from increased trust between crowd workers and businesses. Because crowd workers who have a high level of trust may be better able to follow delivery standards and preserve the privacy and information of clients. Thus, the practical value of our study is that our research findings may benefit crowd workers, crowdsourcers, customers, and crowdsourcing platforms.

The rest of the paper is arranged as follows. Section 2 is the literature review, while Section 3 provides the theoretical background and research hypothesis. Section 4 discusses the research method and empirical results. Section 5 presents the discussion of results, while Section 6 provides the conclusion, limitations, and future research directions.

\section{Literature Review}

2.1. The Origin and Role of Trust. Trust, which refers to an individual's dependence on a partner in the presence of risk, first appeared in the field of psychology [10] and was later applied in relationship marketing research [13]. With the growth and expansion of the market economy, trust issues between enterprises have become more prominent, and research on trust has grown significantly. For example, McAllister [14] divided trust between organizations into cognitive and affective. He defined cognitive trust as believing that the other party has enough ability, including technology, capacity, and knowledge, to achieve the desired results. Affective trust emphasizes the emotional interaction between two parties, focusing on the duration of cooperation when the external environment fluctuates and is driven by emotions and relationships [14]. Inkpen and Tsang [15] pointed out that trust is crucial in organizational relationships and is an important predictor of organizational performance. Fynes et al. [16] concluded that trust between enterprises could reduce opportunistic behaviors in both parties and reduce transaction costs.

In recent years, the relationship between trust and enterprises' operational performance has been the focus of numerous studies. Many scholars have explored the promoting effect of trust on enterprise operational performance from the perspective of third-party logistics integration (e.g., Hofer et al., 2009 [17]; Lai et al., 2013 [18]; and Dai et al., 2015 [19]). Studies have found that the trust between logistics outsourcing enterprises and service providers can promote integration among third-party logistics and boost the operational performance of logistics enterprises $[17,18]$. Developing trust between partners would reduce erratic and uncertain behaviors, reduce supervision costs for both parties, and improve operational performance [19]. The positive effect of trust has been proven to be effective in internet technology (IT) outsourcing enterprises and enhance innovation among enterprises [20, 21].

For crowdsourcing, Blanchard and Markus [22] found that trust in the crowdsourcing platform affects participation behavior, impacting crowdsourcing performance. Similarly, Bauer et al. [23] concluded that trust has an important influence on participants' online social behavior. Norat [24] pointed out that increasing trust among crowd workers is conducive to the continued completion of tasks, reduces the number of abandoned packages in the distribution process, and improves crowdsourcing performance. Analyzing the relationship between trust and crowdsourcing performance, Meng [25], Tu [26], Pang [27], and Yao et al. [7] found that the degree of mutual trust among principal parts (e.g., crowd worker, enterprises, and platforms) can, directly and indirectly, impact crowdsourcing performance.

2.2. Trust in Crowd Logistics. The crowdsourcing operation mode is based largely on the concepts of the sharing economy and open distribution and is driven by the emergence of smartphones, global positioning system (GPS), WLAN, and information and communication technology. This operation mode has been absorbed by the logistics field [6], resulting in a new group of crowdsourcing logistics enterprises (e.g., JD-dada, FlashEx, and MyWays). While some have argued that scholarly research on crowd logistics has significantly lagged behind its current practical applications $[28,29]$, a number of studies have been conducted investigating particular aspects of crowd logistics. For 
example, Chanal [2] argues that crowd logistics can be used to tap idle social resources to solve distribution needs and mitigate shortages in human resources. Carbone et al. [29] believe that crowd logistics can make full use of people's idle time, abilities, and other logistics resources to develop logistics services. Wang et al. [30] proposed applying crowd logistics to solve the last-mile delivery problem, realizing the optimization of real-time logistics distribution. Lin et al. [31] argue that crowd logistics has the advantages of low distribution costs and environmental friendliness.

Numerous scholars have also researched the influencing factors, behavioral decisions, and legal governance issues of crowd logistics. For example, from the perspective of crowdsourcer, Bin et al. [32] explored the main factors influencing the implementation of crowd logistics and concluded that logistics operation mode, external incentives, internal benefits, and security of transformation significantly affect the willingness of enterprises to implement crowd logistics. Liang et al. [33] built a theoretical model, studying the effects of participation motivation, subjective norms, perceived behavior, and satisfaction on crowd workers' continued participation. Guo and Wang [34], using the theory of UTAUT (unified theory of acceptance and use of technology), applied a structural equation model to empirically analyze the influencing factors of crowd workers' participation behavior in crowd logistics. Sun et al. [35] identified risk factors in crowd logistics through literature research and used Fengniao (a crowd logistics application) to conduct an empirical analysis on factors affecting consumer satisfaction. Peng [36] studied the multiple legal risks in crowd logistics and made recommendations, including the establishment of a credit system and information protection mechanisms.

Most studies on crowd logistics largely involve concept definitions, influencing factors, behavioral decisions, and the positive effects of the new logistics mode. Few have explored its negative effects (see Mladenow et al. [6] for a notable exception). Although the current research on crowd logistics involves identifying risk factors, few have analyzed trust and its associated risks generated in this process (see Huang et al. [37] for a notable exception). In particular, how trust between the crowd worker and the logistics enterprise can be further encouraged requires further investigation. In thirdparty logistics, trust is considered a pivotal factor in enhancing the operational performance of enterprises. However, the cooperative relationship under the crowd logistics mode is generated based on the task, with short timelines, weak stability, and poor sustainability. Building trust between the crowd worker and the crowdsourcer and promoting cooperation and synergy are critical to reinforcing the operational performance of crowd logistics enterprises.

\section{Theoretical Background and Hypothesis}

\subsection{Theoretical Background}

3.1.1. Commitment-Trust Theory. Commitment-trust theory is a fundamental theory in relationship marketing. It was first proposed by Morgan and Hunt and is regarded as an important mechanism to promote customer relationships
[13]. According to Morgan and Hunt, commitment and trust are crucial to competitive advantage. Trust determines commitment. It can push the customer to rely on the transactional relationship with the marketer and be willing to make a personal effort to maintain that relationship. The relationship capital between trust and commitment also helps reduce misunderstanding and customer concerns on particular uncertainties and transactional risks [13].

In recent years, this theory has been applied in numerous management studies. For example, Zhu [38] applied commitment-trust theory to empirically analyze the influence of trust on user participation in social media. Yao [39] verified that trust has a positive impact on supply chain performance through the mediating role of synergy. Cui et al. [40] also used this framework to study the influence of trust on online participation willingness and satisfaction in cross-border mobile commerce. These studies show that the commitment-trust theory provides a positive theoretical reference to study participatory behavior in the sharing economy. Since trust is crucial between the crowd worker and the crowdsourcer in the crowd logistics network, we used this theory to explore the influence of trust on the crowd logistics enterprises' operational performance.

3.1.2. Logistics Synergy Theory. Logistics synergy was first analyzed in the United States and has since been studied from different perspectives. Sacaluga [41] posits that logistics synergy mainly refers to the efficient and coordinated operation among various functions, including logistics, to maximize customer demand. Cao and Yang [42] studied the influence of supply chain synergy on enterprise performance. Chen et al. [43] expounded the necessity of enterprise knowledge chain innovation and forwarded corresponding innovation countermeasures using the logistics synergy theory. Zhang et al. [44] applied this theory to the coordinated development mode of rural e-commerce and rural logistics. Based on this theory, Zhang [45] constructed the cross-border e-commerce and cross-border logistics synergy mode and raised a series of measures to promote the value of enterprises. With the continued application of this theory, logistics synergy has increasingly presented the trend of interdisciplinary sharing.

Crowd logistics is mainly supported by internet information technology, where enterprises outsource delivery tasks to the public [6]. The two parties cooperate to share logistics information, technology, and human resources, thus increasing resource allocation efficiency, reducing logistics costs, and enhancing enterprise performance. Crowdsourcing system includes not only enterprises, platforms, and crowd workers but also information, capital, human resources, technology, and other resource elements [37]. Since the synergy of elements within the system has a significant impact on crowdsourcing performance, we first discuss the theory of logistics synergy in studying crowd logistics enterprises' operational performance.

3.2. Research Model Construction. We separate the factors affecting the operational performance of the crowd logistics enterprise into trust (goodwill trust and ability trust) and 
logistics synergy using commitment-trust theory and logistics synergy theory. We propose that goodwill trust, ability trust, and logistics synergy can significantly impact crowd logistics enterprises' operational performance and that logistics synergy plays a mediating role on goodwill trust and ability trust in affecting operational performance. On this basis, a theoretical research model is developed and is presented in Figure 1.

3.3. Hypotheses. Based on literature review and theoretical analysis, this study presents several hypotheses on the relationship between trust, logistics synergy, and crowd logistics enterprises' operational performance.

\subsubsection{Trust and Crowd Logistics Enterprises' Operational} Performance. Trust is considered the foundation of effective cooperation [46]. Trust between enterprises can reduce opportunistic behaviors to maintain long-term benefits with existing partners and obtain specific performance results [47]. Early studies on the integration of third-party logistics found the role of a solid, trusting relationship as crucial in elevating the operational performance of logistics enterprises [17, 18]. Feller et al. [48] concluded that trust is a critical factor affecting the crowd worker's continued participation and can also determine crowdsourcing success. Bauer et al. [23] also found that trust affects the crowd worker's social behavior. Norat [24] further pointed out that enhancing users' trust in crowdsourcing enterprises can boost the enterprises' operational performance.

Trust can be divided into different dimensions in various ways. In this study, trust is divided into two dimensions, based on the studies of Jonathan and Kankanhalli [9], McAllister [14], and Mayer et al. [48]: goodwill trust and ability trust. In the sharing economy, the demand side is largely concerned with whether the resource supplier has the skills and ability to meet its needs and whether it has essential qualities of kindness and integrity [49]. Numerous scholars (e.g., Meng and He, 2020 [49]; Wang, 2011 [50]; Li and Yu, 2011 [51]) have found that ability trust and goodwill trust are key factors driving consumer's behavioral intention in the sharing economy.

In goodwill trust, the enterprise believes that the crowd worker can keep the qualities of honesty and trustworthiness amidst fierce market competition, safeguarding the company's interests [49]. Goodwill trust focuses on the sense of moral obligation and responsibility, which can significantly impact the individual's attitude and behavior and affect the performance of enterprises [50]. Goodwill trust focuses on the quality and intentions of partners, which are conducive to reducing transaction costs and opportunistic tendencies and raising the stability of cooperative behavior and the operational performance of supply chain enterprises [51].

Crowd logistics adopts the idea of the sharing economy in its operation mode, maximizing idle labor resources to perform urban logistics services. However, in actual practice, the loose cooperative relationship between crowd logistics enterprises (crowdsourcer) and the crowd worker is highly uncertain [52]. Crowd workers, for example, are often penalized by companies due to complaints from consumers. When receiving first-time complaints, enterprises often forego investigation and directly blame the crowd worker, at a time when goodwill and trust have not been formed between the two parties. This behavior reduces enthusiasm among crowd workers to participate in crowd logistics, affects their service quality, and adversely impacts the enterprise's operational performance. Accordingly, this study offers the following hypothesis:

H1a: Goodwill trust has a positive impact on crowd logistics enterprises' operational performance

Ability trust refers to the enterprise's belief that crowd workers can achieve their own needs and expectations and perform their duties smoothly. In practice, delivery risks (e.g., vandalizing parcels and revealing customer information) are widespread, given the absence of professional training for crowd workers [53]. If the enterprise, as the demander, chooses to trust the crowd workers' professionalism that they will not harm the interests of the enterprise for their own interests, a healthy cooperative relationship can be formed between the parties, which will improve the performance of the enterprise. Morgan et al. [13] argue that ability trust helps partners not have to repeatedly explain each other's abilities, which helps promote high-quality cooperation, reduces unnecessary supervision and incentives, and advances the response speed of the supply chain. Therefore, the ability trust of the enterprises to connect with crowd workers can help increase their continued willingness and participation, significantly reduce management costs, and raise the company's operational performance. Based on these arguments, we put forward the following hypothesis:

H1b: Ability trust has a positive impact on crowd logistics enterprises' operational performance

\subsubsection{Logistics Synergy and Crowd Logistics Operational} Performance. Synergy results from one party choosing to interact and cooperate with another, given the difficulties of accomplishing its goal by itself [54]. With the growing application of synergetics theory in various disciplines (e.g., economics and engineering), its use in logistics has also increased [55]. Research on logistics synergy mainly focuses on the supply chain, emphasizing cooperation between supply chain functions from multiple dimensions to maximize overall efficiency. Research has shown that logistics synergy in the supply chain positively affects the enterprise's operational performance and that strengthening information resource coordination among enterprises helps improve operational performance $[56,57]$. Wang et al. [8] concluded that logistics synergy is a crucial factor affecting enterprise performance.

In crowd logistics activities, enterprises and crowd workers carry out flexible logistics synergy through advanced management and information technology to achieve common goals. The logistics synergy between the crowdsourcer and the crowd worker through the original boundary of enterprise capital specificity realizes cross-organization sharing and resource allocation. This synergy significantly boosts the operational flexibility of third-party logistics enterprises and improves the level of customer 


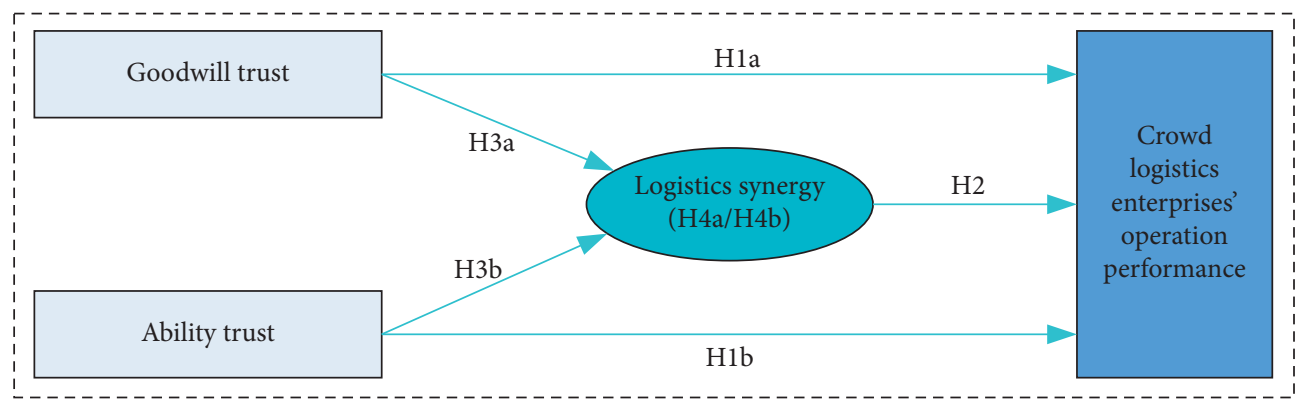

FIgURE 1: Research model.

service. This means logistics synergy is a critical force to promote the crowd logistics enterprises' operational performance. Hence, we propose the following hypothesis:

H2: Logistics synergy has a positive impact on crowd logistics enterprises' operational performance

3.3.3. Trust and Logistics Synergy. Trust is the basis of effective collaboration and plays a positive role in promoting cooperation between enterprises $[45,58]$. Crowd logistics offers delivery invitations to a large group of people in a collaborative way. In this process, trust between the crowd worker and the crowdsourcer may affect the logistics synergy. Saenz et al. [59] found that organizations that lack trust are more likely to reject logistics collaboration. Zhang et al. [60] found that trust is a critical factor that can restrict horizontal logistics synergy. In other words, enterprises that trust each other are more likely to carry out synergistic activities for particular logistics businesses [61].

In the crowd logistics system, the moral level of the crowd worker is a major factor for enterprises to measure synergy. The goodwill trust of the enterprise recognizes that the crowd worker has a moral character of loyalty and integrity and trusts the cooperative behavior of each other [62]. Therefore, we propose the following hypothesis:

H3a: Goodwill trust has a positive effect on logistics synergy

Ability trust encourages enterprises to believe that crowd workers have the strength and ability to complete the task and achieve the targets. This enhances information sharing and promotes cooperative behavior between parties, further improving the degree of synergy [63]. Crowd logistics enterprises pay attention to service quality and delivery efficiency and are likely to choose qualified, competent, and experienced crowd workers [7]. This kind of ability trust can help enterprises reduce synergy costs and enhance crowd logistics synergy with crowd workers. Hence, we propose the following hypothesis:

H3b: Ability trust has a positive effect on logistics synergy

3.3.4. The Intermediary Role of Logistics Synergy. Trust can be a significant factor restraining opportunistic behavior and promote the development of synergistic activities. Efficient synergistic activities have been shown to reduce operating costs and improve customer service quality [16]. In the crowd logistics market, enterprises' trust in crowd workers can help reduce the need for formal contracts, decrease unnecessary logistics links, and increase logistics response speed [12]. Developing trust also promotes the transfer and sharing of information, technology, and other resources between crowd workers and crowdsourcers, thus lowering transaction costs and positively impacting operational performance. Based on these arguments, we propose the following hypotheses:

H4a: Logistics synergy plays a mediating role in the influence of goodwill trust on crowd logistics enterprises' operational performance

H4b: Logistics synergy plays a mediating role in the influence of ability trust on crowd logistics enterprises' operational performance

\section{Research Methodology and Results}

The research method of this paper consists of five steps: (1) questionnaire design, (2) questionnaire pretest, (3) data collection, (4) selection of control variables, and (5) data analysis [37, 64].

4.1. Questionnaire Design. The questionnaire consists of two parts. The first part includes the basic information of the crowd logistics enterprises, including the ownership, annual sales, and the number of years of operation. The second part consists of four latent variables: ability trust, goodwill trust, logistics synergy, and operational performance. The observation items for each latent variable were based on measurement scales developed and verified in previous studies and adjusted according to the practical background of crowd logistics. Table 1 provides the summary of latent variables and observation items used in the study. We used a Likert five-point scale to quantify each observation item ranging from: strongly disagree, disagree, neither agree nor disagree, agree, and strongly agree [65].

4.2. Questionnaire Pretest. Before the actual survey, we pretested the questionnaire and sent it to 12 senior managers of crowd logistics enterprises by e-mail. The managers were from Changsha city, Zhuzhou city, and Xiangtan city. The 
TABLE 1: Observation items for each latent variable.

\begin{tabular}{|c|c|c|}
\hline Latent variables & Observation items & References \\
\hline Goodwill trust (GT) & $\begin{array}{l}\text { H1a-a1: I believe that when the market changes, the crowd worker will } \\
\text { not be inclined to transfer costs to the enterprise } \\
\text { H1a-b1: I believe that the crowd worker pays close attention to the needs } \\
\text { of the enterprise and sincerely cares about the success of the enterprise } \\
\text { H1a-cl: I believe that the crowd worker has sacrificed for the enterprise } \\
\text { in the past }\end{array}$ & $\begin{array}{l}\text { Levin and Cross [66]; } \\
\text { Ganesan [67] }\end{array}$ \\
\hline Ability trust (AT) & $\begin{array}{l}\text { H1b-a2: I believe that the crowd worker has strong working skills, and } \\
\text { working with them can enhance the enterprise's operational } \\
\text { performance } \\
\text { H1b-b2: I think most of the crowd workers are reliable in terms of their } \\
\text { business capability } \\
\text { H1b-c2: In my opinion, the crowd worker meets the task requirements of } \\
\text { the enterprise and can complete the delivery task with high quality }\end{array}$ & $\begin{array}{c}\text { Mcallister }[14] \text {; } \\
\text { Anderson and Narus } \\
{[68]}\end{array}$ \\
\hline Logistics synergy (LS) & $\begin{array}{l}\text { H2-a3: Our enterprise keeps regular feedback and communication with } \\
\text { the crowd worker } \\
\text { H2-b3 : I think when the customer demand change, the enterprise and } \\
\text { the crowd worker can negotiate to develop a flexible workflow } \\
\text { H2-c3: To my way of thing, the enterprise and the crowd worker can } \\
\text { share crowd logistics information in a timely manner }\end{array}$ & $\begin{array}{l}\text { Sinkovic and Roath [69]; } \\
\text { Story et al. [70] }\end{array}$ \\
\hline $\begin{array}{l}\text { Crowd logistics enterprises' } \\
\text { operational performance (CLEOP) }\end{array}$ & $\begin{array}{l}\text { H-a: In my opinion, crowd logistics enterprises can provide excellent } \\
\text { customer service quality } \\
\text { H-b: I think crowd logistics enterprises can respond to customer needs in } \\
\text { a timely manner } \\
\text { H-c: I think the delivery speed of crowd logistics enterprises is fast, and } \\
\text { the delivery reliability is strong }\end{array}$ & Zhao et al. [71] \\
\hline
\end{tabular}

pretest was to identify possible errors, confusing statements, or ambiguous language in the questionnaire. The work took two weeks to finish and was conducted in August 2020. Based on the feedback, modifications were made accordingly.

4.3. Data Collection. The respondents to the actual survey were senior managers of crowd logistics enterprises from the cities of Changsha, Zhuzhou, and Xiangtan in Hunan Province, China. These cities form the "Chang-Zhu-Tan Urban Agglomeration" (see Figure 2). In 2007, the urban agglomeration was approved by the State Council as a national comprehensive reform pilot area for resource efficiency and environment friendliness [72]. Adhering to the concepts of green and shared development, this urban agglomeration has been encouraging crowdsourcing business development in recent years. Crowd logistics is characterized by both sharing and green development [6], and thus, this business mode has been strongly supported by the local government.

The survey was conducted both offline and online (via e-mail, WeChat, and other social software) and was conducted for nearly 3 months, from September to November 2020. On average, the respondents were able to finish the survey in about 7 minutes. While we did not offer material rewards to the respondents, we promised that the participating enterprises would be given priority to cooperate with our team in future logistics experiments and studies. This was received positively by many crowd logistics enterprises. Among the 63 questionnaires sent out, 56 were recovered, equivalent to an overall recovery rate of $88.9 \%$. Fifty questionnaires were valid, resulting in an effective recovery rate of $89.3 \%$. The characteristic distribution of valid sample enterprises is shown in Table 2. In terms of ownership structure, private enterprises accounted for $64.36 \%$, while state-owned enterprises accounted for $23.27 \%$. More than $90 \%$ of the sampled enterprises have been operating for more than 10 years, and nearly $60 \%$ have annual sales of more than 100 million yuan.

4.4. Selection of Control Variables. The factors that remain unchanged or are not evaluated during the experiment are referred to as control variables [73]. To eliminate the potential influence of certain factors, we used some basic information on the respondent's enterprise as control variables. These include the ownership structure of the enterprises, the number of years it has been in business, and its annual sales. The control variables used in this study are listed in Table 2.

4.5. Data Analysis. Partial least squares (PLS) [74] structural equation modeling was used for data analysis and hypotheses testing. PLS is a component-based estimation method widely used in social science research to analyze quantitative data [75]. Compared with LISREL, AMOS, and other methods, PLS is more applicable for quantitative analysis of structural equations with small sample sizes and can process non-normally distributed data samples and test higher-order structural equation models [76]. In this paper, trust was used as a second-order latent variable, and PLS modeling can more accurately reflect the relationship between higher-order model variables. Furthermore, trust 


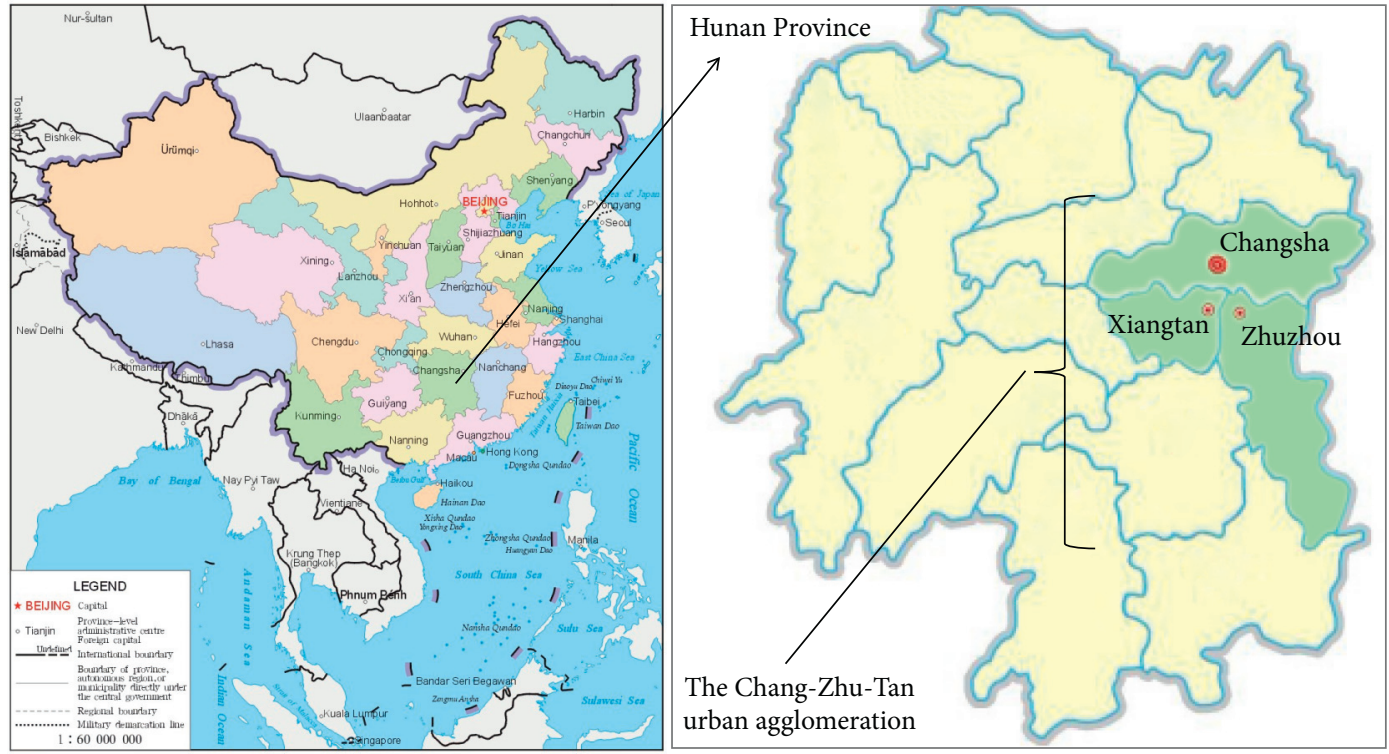

FIgURE 2: The cities where the data were collected.

TABle 2: Descriptive statistical information of crowd logistics enterprises.

\begin{tabular}{lcc}
\hline Category & Item & $\begin{array}{c}\text { Ratio } \\
(\%)\end{array}$ \\
\hline & The private enterprise & 64.36 \\
Ownership structure & Wholly foreign-owned & 4.47 \\
& enterprise & \\
& Sino-foreign joint venture & 7.90 \\
& State-owned enterprises & 23.27 \\
\hline Business years & $<10$ years & 9.41 \\
& $10-19$ years & 37.62 \\
& $\geq 20$ years & 52.97 \\
\hline Annual sales (yuan, & $<1$ million & 1.98 \\
CNY) & 5.01 million-5 million & 4.95 \\
& 10.01 million-50 million & 1.49 \\
& 50.01 million-100 million & 6.44 \\
& $\geq 100$ million & 25.25 \\
\hline
\end{tabular}

between crowd workers and logistics companies is difficult to assess in the usual sense. SEM-PLS is well suited to analyze survey data in such complicated scenarios [76].

4.5.1. Reliability and Validity Tests. Reliability and validity tests are used to verify whether the measured scale is scientific [74]. In this study, Cronbach's alpha (CA) and average variance extracted (AVE) values were used. The lowest CA value was $0.814(\geq 0.7)$, and the lowest $C R$ value was 0.889 $(\geq 0.7)$, indicating good reliability in the study's scale design [77]. The outer loading values for all observed variables were greater than 0.7 (the minimum is 0.807 ), as shown in Figures 3-5. The calculated AVE values were greater than 0.7 (the minimum is 0.729 ), as shown in Table 3, indicating that the indicator data had good convergence validity [77]. In addition, the AVE square root was greater than the correlation coefficient between latent variables. This suggests no collinearity among the latent variables and good discriminative validity for the model (as shown in Table 4) [77].

Considering that common method bias (CMB) may adversely affect the results of the study [78], a method of procedural control was used [46]. We first conducted a pretest before the formal questionnaire survey, which eliminated the problems caused by semantic deviations or difficulty of respondents to understand the questions. Then, we informed the respondents before the survey that their personal and business information will be kept confidential throughout the study [37].

4.5.2. Hypothesis Testing. Three models were constructed using SmartPLS3.0 software to analyze the following: the influence of goodwill trust and ability trust on logistics synergy (model 1, see Figure 3); the influence of goodwill trust, ability trust, and logistics synergy on the crowd logistics enterprises' operational performance (model 2, see Figure 4); and the mediating role of logistics synergy in the process of trust influencing crowd logistics enterprises' operational performance (model 3, see Figure 5). The first two models were compared with model 3 to determine whether logistics synergy plays a mediating role.

In the three validation models, the minimum $R^{2}$ value was 0.667, indicating good explanatory ability for the constructed research model had [77]. Based on the results shown in Table 5, H1b, H2, H3b, H4a, and H4b passed the hypothesis test ( $p$-value $\leq 0.05[77,79]$ ), while $\mathrm{H} 1 \mathrm{a}$ and $\mathrm{H} 3 \mathrm{a}$ (the path coefficient is negative, contrary to our hypothesis) did not pass the hypothesis test ( $p$-value $>0.05[77,79])$.

\subsubsection{Findings}

(i) Confirmed hypothesis

The results suggest that ability trust positively affects the crowd logistics enterprises' operational performance ( $\mathrm{H} 1 \mathrm{~b}$ passed the hypothesis test), similar to the 


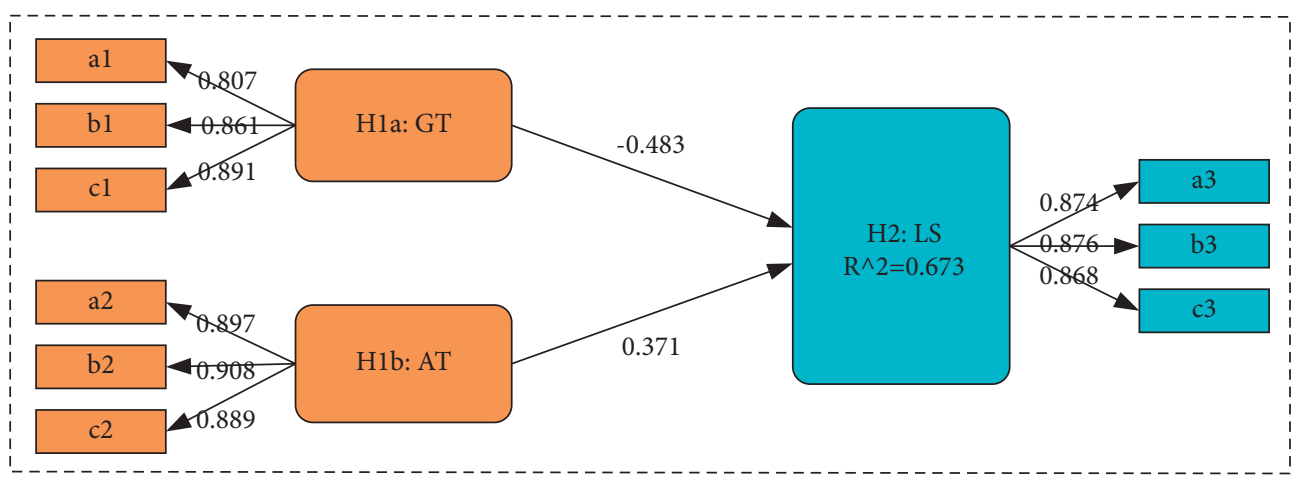

Figure 3: The model 1 results.

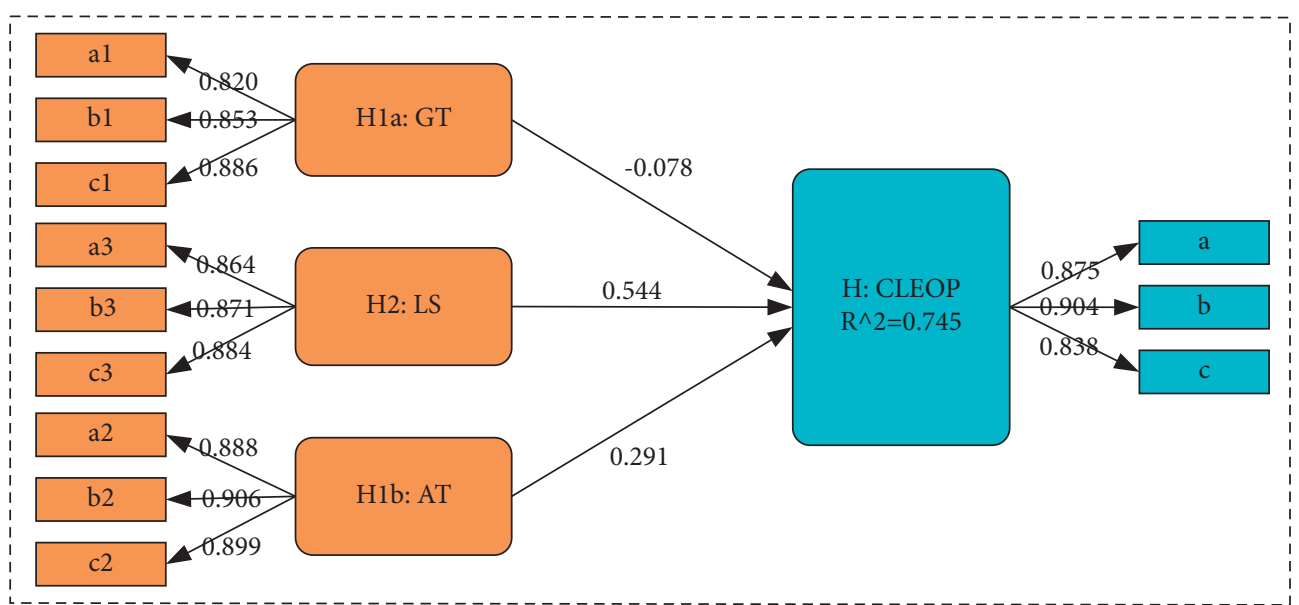

FIgURE 4: The model 2 results.

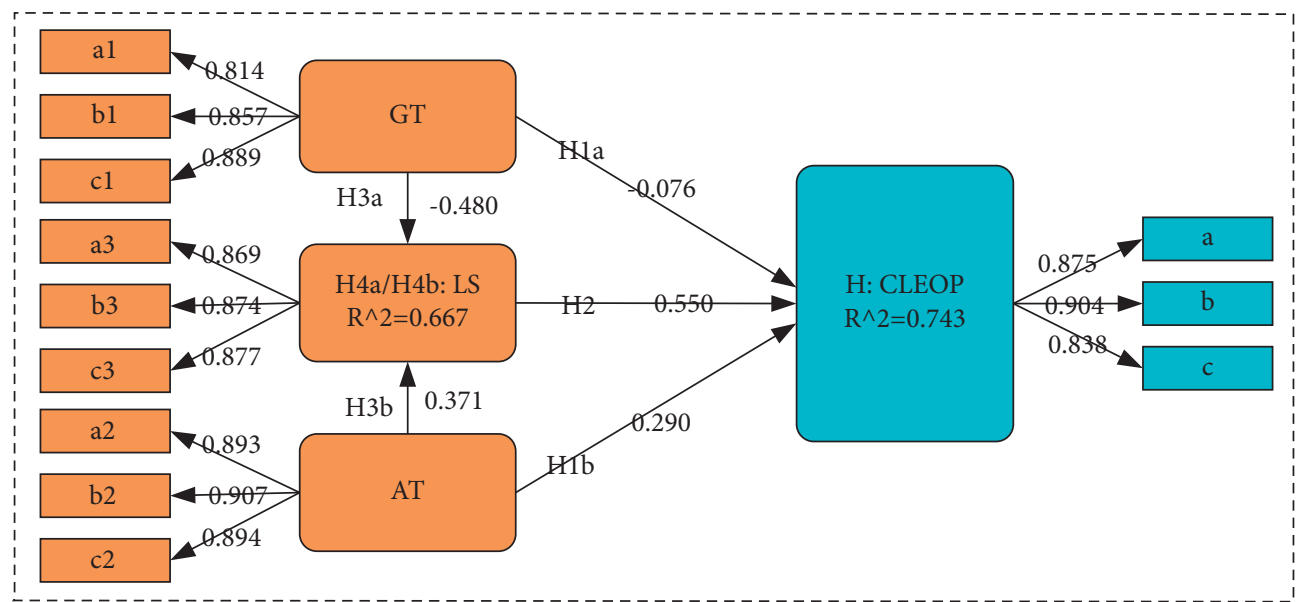

FIgURE 5: The model 3 results.

conclusions of some previous studies (e.g., Luo et al. [11], Hofer et al. [17], and Cheng et al. [80]). This means that if an enterprise has trust in its crowd workers' abilities to complete the delivery work, it will have a positive impact on the company's operational performance. Therefore, enterprises can improve the effectiveness of cooperative relationships and increase operational performance by developing and cultivating trust with their crowd workers.

Ability trust positively affects logistics synergy (H3b passed the hypothesis test). If the crowd logistics enterprise trusts that its crowd workers have the skills to complete the delivery task with high quality, it will help promote synergistic activities. Previous studies have 
TABLE 3: Reliability and validity test results.

\begin{tabular}{lccr}
\hline Latent variables & CA & CR & AVE \\
\hline AT & 0.880 & 0.926 & 0.806 \\
GT & 0.814 & 0.889 & 0.729 \\
LS & 0.844 & 0.906 & 0.762 \\
CLEOP & 0.844 & 0.906 & 0.762 \\
\hline
\end{tabular}

TABLE 4: Average variance extracted (AVE) square root and factor correlation coefficient.

\begin{tabular}{lcccc}
\hline & H1a & H1b & H2 & \\
\hline GT & $\mathbf{0 . 8 5 4}$ & & & \\
AT & -0.841 & $\mathbf{0 . 8 9 8}$ & $\mathbf{0 . 8 7 3}$ \\
LS & -0.792 & 0.774 & 0.835 & $\mathbf{0 . 8 7 3}$ \\
CLEOP & -0.755 & 0.780 & & \\
\hline
\end{tabular}

Note: diagonal elements (the bold values) are the square root of average variance extracted (AVE).

TABLE 5: Results of hypotheses testing.

\begin{tabular}{|c|c|c|c|c|c|c|c|c|c|}
\hline \multirow[b]{2}{*}{ Path } & \multicolumn{3}{|c|}{ Model 1} & \multicolumn{3}{|c|}{ Model 2} & \multicolumn{3}{|c|}{ Model 3} \\
\hline & Path coefficient & $t$-value & $p$-value & Path coefficient & $t$-value & $p$-value & Path coefficient & $t$-value & $p$-value \\
\hline $\mathrm{GT} \longrightarrow \mathrm{LS}$ & -0.483 & 3.231 & 0.001 & & & & -0.480 & 3.282 & 0.001 \\
\hline $\mathrm{AT} \longrightarrow \mathrm{LS}$ & 0.371 & 2.205 & 0.028 & & & & 0.371 & 2.256 & 0.024 \\
\hline $\mathrm{LS} \longrightarrow \mathrm{CLEOP}$ & & & & 0.544 & 4.001 & $\leq 0.001$ & 0.550 & 4.406 & $\leq 0.001$ \\
\hline $\mathrm{GT} \longrightarrow \mathrm{CLEOP}$ & & & & -0.078 & 0.658 & 0.511 & -0.076 & 0.699 & 0.485 \\
\hline $\mathrm{AT} \longrightarrow \mathrm{CLEOP}$ & & & & 0.297 & 2.254 & 0.025 & 0.290 & 2.206 & 0.028 \\
\hline
\end{tabular}

confirmed the positive effect of trust on synergy. For example, Wang et al. [8] found that mutual trust between suppliers and crowd workers can enhance their degree of synergy, provide enterprises with a competitive advantage, and help meet consumer needs.

Logistics synergy positively influences crowd logistics enterprises' operational performance ( $\mathrm{H} 2$ passed the hypothesis test), and logistics synergy plays a mediating role in how ability trust positively affects operational performance ( $\mathrm{H} 4 \mathrm{~b}$ passed the hypothesis test). This conclusion is similar to the findings of Erik [56] and Frank et al. [57]. Lu and Gao [81] believe that a good synergistic relationship between employees and enterprises is crucial for the success of supply chain operations. When traditional logistics enterprises carry out promotional activities on various e-commerce platforms, they often face multiple problems, such as overcrowded express warehouses and insufficient transport capacity. Through logistics synergy with crowd workers, enterprises can promptly share workforce, logistics, information, and other resources. This considerably reduces the costs of purchasing special delivery vehicles and recruiting formal employees. And with timely feedback, this system can flexibly respond to the fluctuations in customer needs, greatly improving service quality and customer satisfaction. The results show that ability trust not only affects the enterprises' operational performance directly but also has an indirect effect through the intermediary variable of logistics synergy. To promote the positive effect of ability trust in operational performance, logistics enterprises should build a good synergistic relationship with their crowd workers and regularly implement synergistic activities.

The results also show that logistics synergy plays a mediating role in how goodwill trust affects operational performance ( $\mathrm{H} 4 \mathrm{a}$ passed the hypothesis test). The results show that logistics synergy amplifies the inhibitory effect of goodwill trust on operational performance, which may be caused by the maturation of the crowdsourcing market and the increasing diversification of crowd workers. In the sharing of information, technology, and resources, goodwill trust between enterprises and crowd workers can be established relatively quickly. This trust may lead to a relaxed environment for synergy, leading crowd workers to take advantage and have opportunistic behaviors. These outcomes would not be conducive to the improvement of the crowd logistics enterprises' operational performance.

(ii) Unconfirmed hypothesis

Goodwill trust was found to have no significant effect on the crowd logistics enterprises' operational performance (H1a did not pass the hypothesis test). This conclusion is similar to the findings of Ganesan [67]. One possible explanation for this finding is that enterprises are mainly concerned with task completion when selecting crowd workers. Goodwill trust depends largely on the quality and intentions of partners and is a soft resource that gradually develops over long-term communication and collaboration. Since crowd workers are external temporary 
hires, enterprises are not compelled to have longterm communication, mutual familiarity, and identification. Moreover, goodwill trust is not as easily perceivable as ability trust. These could explain why goodwill trust did not significantly affect the operational performance of crowd logistics enterprises.

Goodwill trust negatively affects logistics synergy (H3a did not pass the hypothesis test), which is contrary to the research hypothesis of this paper. In most cases, the goodwill trust of the enterprise to the crowd worker can only be obtained by short-term emotional perception, which can easily lead to subjective wrong judgment. Some crowd workers who do not have the goodwill quality enter the enterprise, while some with excellent qualities are unjustly expelled from the market. If this goes on for a long time, the wrong goodwill trust cannot support the continuous development of logistics synergy between the two parties. Besides, in the absence of legal contracts, the crowd worker may take opportunistic behavior in the complex external environment, for example, the disclosure of some hidden, critical, and valid information (e.g., consumer's address and preference) shared by the enterprise. This will seriously violate consumer privacy and reduce customer satisfaction. Therefore, it may inhibit the positive effect of logistics synergy.

\section{Discussion}

In this paper, we proposed a total of seven research hypotheses, five of which have been verified. These five hypotheses are about the impact of trust on the crowd logistics enterprises' operational performance. The findings suggest that ability trust and logistics synergy are significant variables that directly impact crowd logistics enterprises' operational performance. Ability trust is positively correlated with logistics synergy; the more ability-trust logistics enterprises have in the crowd workers, the more conducive it will be to the collaborative operation of logistics enterprises. Logistics synergy was also found to play a mediating role between trust (both goodwill trust and ability trust) and operational performance. These findings largely support the conclusions of existing literature. These findings are similar to those of some previous studies (e.g., Ye and Kankanhalli, 2017 [9] and Huang et al., 2020 [37]), and we expect that these findings will be echoed in other contexts. The following are some theoretical and practical implications based on the results of this study.

5.1. Theoretical Implications. First, this study adds to the growing literature about the role of trust in crowd logistics. Crowd logistics has become a major research topic, with numerous studies being conducted from varying perspectives. For example, studies have been made analyzing the influencing factor affecting continued participation in crowd logistics, from the perspective of crowd workers (e.g., Ye and
Kankanhalli [9], Liang et al. [33], and Huang et al. [37]). Several studies have investigated the influencing factors of implementation from the perspective of enterprises or platforms (e.g., Yao et al. [7], Bin et al. [32], and Bin et al. [64]). Some have explored the environmental sustainability of crowd logistics (e.g., Mladenow et al. [6], Rai et al. [28], and Lin et al. [31]). This paper focuses on the issue of trust, which provides a new insight for establishing a good cooperative relationship between the enterprise and the crowd worker.

Second, this study comprehensively investigates the impact of logistics synergy on the operational performance of crowd logistics enterprises. The perspectives of crowd workers and crowd logistics enterprises are taken into account and integrated into a theoretical model and analysis, as well as factoring in the effects of logistics synergy [41]. The addition of logistics synergy factors significantly improves the discussion on the relationship between the crowd worker and the enterprises, providing new insights into the subject matter.

Finally, this paper expands the application of commitment-trust theory in crowd logistics research. Informal cooperation between the crowd worker and the crowd logistics enterprises requires more trust to maintain the relationship between the two parties. This suggests that this theory can be used and expanded to other related disciplines (e.g., Zhu [38], Yao [39], and Cui et al. [40]). In particular, there is no legal, contractual relationship between the two parties.

5.2. Practical Implications. First, enterprises and platforms should scientifically evaluate the abilities of crowd workers and promote trust relationships with crowd workers. The results show that ability trust has a significant positive impact on the operational performance of crowd logistics enterprises. Therefore, enterprises should establish an assessment method in selecting experienced and skilled crowd workers to ensure that the crowd worker can fulfill their work on time [37] and provide high-quality delivery service [32]. Enterprises should also construct a personal credit system and a service quality evaluation system in their operations and adopt an elimination system for crowd workers with low distribution efficiency, high credit risk, and poor service levels. These measures can help enterprises reduce their distrust against opportunistic behavior when the environment is changing or unpredictable (e.g., the emergence of peak orders and the appearance of bad weather).

Second, enterprises should strengthen crowd logistics mechanisms that enhance synergistic efficiency. The results show that logistics synergy is a significant mediating variable increasing the operational performance of enterprises. In crowd logistics, enterprises and crowd workers have broken through the traditional boundaries of enterprise capital specificity, raising higher requirements on cross-organizational sharing, resource allocation, and collaborative logistics operations $[6,28]$. Therefore, enterprises should maintain open communication with their crowd workers, 
sharing timely internal and external logistics information and quickly responding to changes in the external environment. Building sound information feedback and sharing mechanism is essential to ensure that logistics information can be sent and received accurately, timely, and efficiently and raise the speed and reliability of delivery services.

Finally, enterprises should invest in skills training for crowd workers. This study found that most crowd workers registered on the crowdsourcing platform are part-time personnel who have not received standardized professional training. This has resulted in the uneven quality of services, affecting enterprises' operational performance [6]. Enterprises should conduct systematic training for part-time staff, particularly those involved in crowd delivery operations [37]. Enterprises should also regularly carry out skills development on safety management and risk prevention and provide other relevant training to their crowd workers to improve their professional skills and minimize risk concerns.

\section{Conclusions}

With the emergence of the sharing economy, huge demands for logistical services have created the distribution mode of crowd logistics [82]. In route selection and optimization, the use of information communication, satellite location, and navigation provides crucial technical support for the development of crowd logistics. Trust and synergy between crowd workers and the crowdsourcer, however, have become essential challenges in the growth and development of crowd logistics in day-to-day operations. To address some of the current knowledge gaps on the subject matter, this study analyzed the impact of trust between crowd logistics enterprises and crowd workers on operational performance and integrated logistics synergy into the theoretical model. The results indicate that ability trust and logistics synergy are significant variables, directly increasing the operational performance of crowd logistics enterprises. Ability trust was also found to be positively correlated with logistics synergy. The results also show that logistics synergy plays a mediating role between trust (both goodwill trust and ability trust) and operational performance. This work focuses on the examination of the trust relationship between the crowd worker and the crowdsourcer, which is beneficial to promoting the sustainable development of urban logistics.

Based on the results, we recommend that logistics enterprises and platforms evaluate their crowd workers' capabilities and promote trust relationships with them. Enterprises should strengthen crowd logistics mechanisms that stimulate collaborative efficiency. Enterprises must invest in training and developing their crowd workers to boost their abilities and encourage trust, which would eventually enhance their operational performance.

There are some limitations to this study. First, the conclusions may have some regional characteristics. The study area was the Chang-Zhu-Tan urban agglomeration, and some of the results may have been affected by local factors. Future studies can focus on other regions and other scales and compare the results of this study. Second, this paper focused on the influence of trust on operational performance and did not consider other factors that could have affected the results, such as incentive mechanisms and satisfaction. Future research should consider the impact of other factors on the operational performance of crowd logistics enterprises. Third, the commitment-trust theory and logistics synergy theory are applied to this study. Different theoretical foundations may necessitate different factors to be examined, and additional research would be required. Fourth, this study surveyed mainly senior managers. Future studies should consider surveying crowd workers and compare the results of this study. Finally, as part of the industry 4.0 development process, we must continue to pay close attention to and investigate the relationship between crowd workers and logistics companies. Crowd workers are mostly managed by platform algorithms rather than actual managers in the context of the rapid growth of computer algorithms. Therefore, how enterprises handle the balance between managers and platform algorithms has a big impact on how crowd workers and logistics companies trust each other.

\section{Data Availability}

If interested scholars have data requirements, please contact the second author by e-mail (xiaox3731@gmail.com).

\section{Conflicts of Interest}

The authors declare that they have no conflicts of interest.

\section{Acknowledgments}

This work was supported by the National Social Science Foundation of China (grant no. 19BGL177) and the MOE (Ministry of Education in China) Project of Humanity and Social Science Foundation (grant no. 18YJA630001).

\section{References}

[1] V. Ramaswamy and F. J. Gouillart, The Power of Co-creation: Build it with Them to Boost Growth, Productivity, and Profits, Simon and Schuster, New York, NY, USA, 2010.

[2] V. Chanal and M. L. Caron-Fasan, "How to invent a new business model based on crowdsourcing: the Crowdspirit ${ }^{\circledR}$ case," in Proceedings of the Conférence de l'Association Internationale de Management Stratégique, pp. 1-27, SophiaAntipolis, France, May 2008.

[3] B. L. R. Ab, P. Yoonhee, and M. Ha, "Crowdsourcing-harnessing the masses to advance health and medicine, a systematic review," Journal of General Internal Medicine, vol. 29, no. 1, pp. 187-203, 2014.

[4] H. Q. Qiu, "Research on the influencing factors of public participation behaviors in crowdsourcing logistics based on TAM model," China Business and Market, vol. 32, no. 4, pp. 110-119, 2018.

[5] Dada group, "Introduction of dada express business," 2021, https://about.imdada.cn/.

[6] A. Mladenow, C. Bauer, and C. Strauss, ““””: the contribution of social crowds in logistics activities," International Journal of Web Information Systems, vol. 12, no. 3, pp. 379-396, 2016. 
[7] S. J. Yao and Z. L. Fan, "Customer participation, resource synergy and enterprise innovation performance:an empirical study based on crowdsourcing platform," Journal of Nanjing Tech University(Social Science Edition), vol. 18, no. 1, pp. 99-110, 2019.

[8] X. Y. Wang, Y. J. Zhang, and L. Z. Ran, "Scale development of logistical synergistic capability of enterprises and its effect on market orientation and performance relationship," Journal of Management Science, vol. 31, no. 5, pp. 56-73, 2018.

[9] H. Ye and A. Kankanhalli, "Solvers' participation in crowdsourcing platforms: examining the impacts of trust, and benefit and cost factors," The Journal of Strategic Information Systems, vol. 26, no. 2, pp. 101-117, 2017.

[10] A. Zaheer, B. Mcevily, and V. Perrone, "Does trust matter? Exploring the effects of interorganizational and interpersonal trust on performance," Organization Science, vol. 99, no. 2, pp. 141-159, 1998.

[11] L. Luo, C. Liu, and X. D. Zhao, "Impact of trust on 3PL integration and performance," Journal of Beijing Union University, vol. 29, no. 3, pp. 80-86, 2015.

[12] Q. S. Wang, Y. G. Wang, and C. M. Chen, "The experimental analysis of the roles of third party trust service on online purchase intentions," Business Management Journal, vol. 31, no. 7, pp. 102-109, 2009.

[13] R. M. Morgan and S. D. Hunt, "The commitment-trust theory of relationship marketing," Journal of Marketing, vol. 58, no. 3, pp. 20-38, 1994.

[14] D. J. Mcallister, "Affect and cognition- based trust as foundations for interpersonal cooperation in organizations," Academy of management journal, vol. 38, no. 1, pp. 24-59, 1995.

[15] A. C. Inkpen and E. W. K. Tsang, "Social capital, networks, and knowledge transfer," Academy of Management Review, vol. 30, no. 1, pp. 146-165, 2005.

[16] B. Fynes and C. Voss, "The impact of supply chain relationship quality on quality performance," International Journal of Production Economics, vol. 96, no. 3, pp. 339-354, 2005.

[17] A. Hofer, A. Knemeyer, and M. Dresner, "Antecedents and dimensions of customer partnering behavior in logistics outsourcing relationships," Journal of Business Logistics, vol. 30, no. 2, pp. 141-159, 2009.

[18] F. Lai, Z. Chu, Q. Wang, and C. Fan, "Managing dependence in logistics outsourcing relationships: evidence from China," International Journal of Production Research, vol. 51, no. 10, pp. 3037-3054, 2013.

[19] J. Dai, L. Xie, and Q. Wang, "The impact of the third party logistics integration on logistics service quality, partnership and corporate operational performance," Management Review, vol. 27, no. 5, pp. 190-199, 2015.

[20] W. F. Liu and S. Z. Ai, "An empirical study on the factors influencing firm performance in IT outsourcing," Chinese Journal of Management Science, vol. 22, no. 2, pp. 142-148, 2014.

[21] L. Li, Research on the Influences of Open Innovation Capability on Operating Performance under the Moderation of Openness, Nanjing University of Aeronautics and Astronautics, Nanjing, China, 2016.

[22] C. Blanchard and Y. Markus, "Innovation contests, open innovation, and multiagent problem solving," Management Science, vol. 54, no. 9, pp. 1529-1543, 2008.

[23] C. Bauer, A. Mladenow, and C. Strauss, Fostering Collaboration by Location-Based Crowdsourcing, pp. 1-8, Springer, Berlin, Germany, 2014.
[24] J. Norat, "Crowdsourcing with all-pay auctions: a field experiment on taskcn," Management Science, vol. 60, no. 8, pp. 2020-2037, 2015.

[25] T. Meng, Y. Zhang, and D. H. Dong, "The research on influencing factors of crowdsourcing participating behavior based on wickey model," China Soft Science, no. 12, pp. 112-123, 2014.

[26] S. L. Tu, "Research on China's tourism logistics network construction based on crowdsourcing," Journal of Jiangxi University of Finance and Economics, no. 4, pp. 42-48, 2015.

[27] J. G. Pang, "The risk management mechanism of crowdsourcing community innovation," China Soft Science, no. 2, pp. 183-192, 2015.

[28] H. B. Rai, S. Verlinde, J. Merckx, and C. Macharis, "Crowd logistics: an opportunity for more sustainable urban freight transport?" European Transport Research Review, vol. 9, no. 3, p. 39, 2017.

[29] V. Carbone, A. Rouquet, and C. Roussat, "The rise of crowd logistics: a new way to Co-create logistics value," Journal of Business Logistics, vol. 38, no. 4, pp. 238-252, 2017.

[30] Y. Wang, D. Zhang, Q. Liu, F. Shen, and L. H. Lee, “Towards enhancing the last-mile delivery: an effective crowd-tasking model with scalable solutions," Transportation Research Part E: Logistics and Transportation Review, vol. 93, pp. 279-293, 2016.

[31] J. Lin, W. Zhou, and L. Du, "Is on-demand same day package delivery service green?" Transportation Research Part D Transport \& Environment, vol. 61, pp. 118-139, 2017.

[32] H. Bin, H. F. Wang, and G. J. Xie, "Study on the influencing factors of crowdsourcing logistics under sharing economy," Management Review, vol. 031, no. 8, pp. 219-229, 2019.

[33] X. P. Liang, L. X. Huang, and J. Jiang, "Research on antecedent factors of solvers' continuous participation in crowdsourcing logistics," Journal of Business Economics, vol. 07, pp. 5-15, 2017.

[34] J. Guo and J. W. Wang, "Research on the effect factors of participation behavior to the crowdsourcing logistics based on the UTAUT," Operations Research and Management Science, vol. 26, no. 11, pp. 1-6, 2017.

[35] A. Sun and M. K. He, "Identification and analysis of crowdsourcing logistics risk based on structural equation model," Modernization of Management, vol. 37, no. 6, pp. 111-115, 2017.

[36] X. Peng, "Study on the legal management of crowdsourcing logistics in China," China Business and Market, vol. 33, no. 4, pp. 113-120, 2019.

[37] L. Huang, G. Xie, J. Blenkinsopp, R. Huang, and H. Bin, "Crowdsourcing for sustainable urban logistics: exploring the factors influencing crowd workers' participative behavior," Sustainability, vol. 12, no. 8, p. 3091, 2020.

[38] T. Zhu, Research on Uers' Relationships' Development, Maintenance, Deepening Based on the Evolvement of Social Media, Huazhong University of Science and Technology, Wuhan, China, 2019.

[39] P. J. Yao, The Moderating Effects of Information Sharing on Supply Chain Performance: Research on Fruit Farmers' Feeling of Relationship Quality to Wholesaler, Yunnan University of Finance and Economics, Yunnan, China, 2019.

[40] Y. Cui, J. Mou, J. Cohen, Y. Liu, and K. Kurcz, "Understanding consumer intentions toward cross-border m-commerce usage: a psychological distance and commitment-trust perspective," Electronic Commerce Research and Applications, vol. 39, Article ID 100920, 2019. 
[41] J. B. Donald and J. K. David, Logistical Management: The Integrated Supply Chain Pross, China Machine Press, Beijing, China, 1999.

[42] W. J. Cao and W. S. Yang, "Coordination of agricultural product supply chain based on agricultural insurance and organizational form optimization," Journal of Agro-Forestry Economics and Management, vol. 16, pp. 34-42, 2017.

[43] Y. F. Chen, S. L. Wang, and J. Zheng, "Innovation of enterprise knowledge chain under the background of green manufacturing-logistics co-evolution," Science and Technology Management Research, vol. 39, no. 9, pp. 192-196, 2019.

[44] C. Zhang, G. S. Zhang, and Y. L. Wang, "Co-evolution and policy optimization of rural E-commerce and rural logistics under government poverty alleviation," Journal of Beijing Jiaotong University, vol. 19, no. 1, pp. 98-105, 2020.

[45] X. H. Zhang, "Research on collaboration of cross-border E-commerce and cross-border logistics under the belt and road initiative," Contemporary Economic Management, vol. 42, no. 4, pp. 27-32, 2020.

[46] M. Deutsch, "The effect of motivational orientation upon trust and suspicion," Human Relations, vol. 13, no. 2, pp. 123-139, 1960.

[47] F. Joseph, F. Patrick, H. Jeremy, and O. R. Philip, “Orchestrating' sustainable crowdsourcing: a characterisation of solver brokerages," The Journal of Strategic Information Systems, vol. 21, no. 3, pp. 216-232, 2012.

[48] R. C. Mayer, J. H. Davis, and F. D. Schoorman, "An integrative model OF organizational trust," Academy of Management Review, vol. 32, no. 2, 2007.

[49] T. Meng and C. He, "An Investigation on the trust mechanism in the Sharing Economy in the perspective of role," Journal of Guizhou University of Finance and Economics, no. 4, pp. 40-49, 2020.

[50] X. Wnag, The Relationship Study on Network Organization Relationship Interaction and Network Organizational Efficiency, Tianjin University, Tianjin, China, 2011.

[51] S. C. Li and W. G. Yu, "Research on mechanisms of antecedents of manufacturers' long-term orientation towards suppliers," Journal of Management Science, vol. 24, no. 6, pp. 79-92, 2011.

[52] X. Q. Yang, "Crowd logistics rules are the soul of management," Sino Foreign Management, no. 3, pp. 48-49, 2016.

[53] A. Mladenow, C. Bauer, and C. Strauss, Crowdsourcing in Logistics: Concepts and Applications Using the Social Crowd, pp. 244-251, ACM, Belgium, Europe, 2015.

[54] A. Persaud, "Enhancing synergistic innovative capability in multinational corporations an empirical investigation," Journal of Product Innovation Management, vol. 22, no. 5, pp. 412-429, 2005.

[55] H. Zhou, Research on Evaluation of Operational Capability of Agricultural Products Logistics Enterprises Based on Synergetic Theory, Southwest Jiaotong University, Sichuan, China, 2017.

[56] S. Erik, "Logistics collaboration in supply chains: practice vs. theory," International Journal of Logistics Management, vol. 18, no. 2, pp. 274-293, 2007.

[57] M. Frank, T. Becker, and M. Gogolla, "Interoperability of logistics artifacts: an approach for information exchange through transformation mechanisms," in Proceedings of the Ldic-International Conference on Dynamics in Logistics, Germany, October 2016.

[58] H. T. Li and Y. X. Sun, "Trust, cooperation and firm performance," Modern Management Science, no. 3, pp. 23-24, 2013.
[59] M. Saenz, E. Ubaghs, and A. I. Cuevas, "A Enabling horizontal collaboration through continuous relational learning," Springerbriefs in Operations Research.vol. 28, no. 7, pp. 113-135, 2014.

[60] X. Y. Zhang, Z. Z. Sun, and J. Hu, “The constraints and their function mechanism of horizontal logistics collaboration in western logistics cluster based on grounded theory - case study of five provinces and municipalities," Journal of Business Economics, no. 9, pp. 5-18, 2019.

[61] P. Knorringa and J. Meyer-Stamer, "New dimensions in local enterprise cooperation and development: from clusters to industrial districts," Stamer, no. 9, pp. 231-235, 1998.

[62] X. M. Zhang and W. Chen, "Trust, relationship commitment and cooperative performance in supply chain - an empirical study based on the perspective of knowledge trading," Studies in Science of Science, vol. 29, no. 12, pp. 1865-1874, 2011.

[63] Y. Liu, J. Q. Xue, and T. Liu, "An empirical research of the impacts of attitudinal commitment and satisfaction on knowledge transfer," Forecasting, no. 6, pp. 7-13, 2007.

[64] H. Bin, F. Zhao, G. J. Xie et al., "Crowd-sourcing a way to sustainable urban logistics: What Factors Influence Enterprises' Willingness to Implement Crowd Logistics," IEEE Access, vol. 8, 2020.

[65] A. Pervez, A. A. Shah, M. Sheikh, and F. A. Prodhan, "FuzzyLikert scale based assessment of marketing risk faced by the hybrid rice growers of Bangladesh," Agricultural Economics, vol. 60, no. 1, pp. 9-22, 2019.

[66] Z. Daniel and R. C. Levin, "The strength of weak ties you can trust: the mediating role of trust in effective knowledge transfer," Management Science, vol. 50, no. 11, pp. 1477-1490, 2004.

[67] S. Ganesan, "Determinants of long-term orientation in buyerseller relationships," Journal of Marketing, vol. 58, no. 2, pp. 1-19, 1994.

[68] J. C. Anderson and J. A. Narus, "A model of distributor firm and manufacturer firm working partnerships," Journal of Marketing Research, vol. 54, no. 1, pp. 42-58, 1990.

[69] R. R. Sinkovics and A. S. Roath, "Strategic orientation, capabilities and performance in manufacturer-3PL," Relationships Journal of Business Logistics, vol. 25, no. 2, pp. 43-64, 2004.

[70] V. M. Story, C. Raddats, J. Burton, J. Zolkiewski, and T. Baines, "Capabilities for advanced services: a multi-actor," Perspective Industrial Marketing Management, vol. 60, no. 2, pp. 54-68, 2017.

[71] X. Zhao, B. Huo, B. Flynn, and J. H. Y. Yeung, "The impact of power and relationship commitment on the integration between manufacturers and customers in a supply chain," Journal of Operations Management, vol. 26, no. 3, pp. 368388, 2008.

[72] National Development and Reform Commission PRC, "Notice of the national development and reform commission on approving wuhan metropolitan circle and changshazhuzhou-xiangtan urban agglomeration as the national comprehensive supporting reform pilot areas for the construction of a resource-conserving and environment-friendly society," 2021, https://www.ndrc.gov.cn/xxgk/zcfb/tz/201005/ t20100511_965538_ext.html.

[73] "Wikipedia. Control variable," 2021, https://en.wikipedia.org/ wiki/Control_variable.

[74] J. P. Weir, "Quantifying test-retest reliability using the intraclass correlation coefficient and the SEM," The Journal of Strength \& Conditioning Research, vol. 19, no. 1, p. 231, 2005. 
[75] J. Hulland, "Use of partial least squares (PLS) in strategic management research: a review of four recent studies," Strategic Management Journal, vol. 20, no. 2, pp. 195-204, 2015.

[76] G. F. Li and Y. N. Meng, "Comprehensive evaluation on the performance of S\&T activities in universities subordinated to the ministry of education-an empirical study based on the PLS path model," $R \& D$ Management, vol. 25, no. 2, pp. 95-106, 2013.

[77] S. Ahmad and M. Wan, "The importance-performance matrix analysis in partial least square structural equation modeling (PLS-SEM) with smartpls 2.0 M3," International Journal of Mathematics Research, vol. 3, no. 1, pp. 1-14, 2014.

[78] S. Wingate, E. Sng, and P. D. Loprinzi, "The influence of common method bias on the relationship of the socio-ecological model in predicting physical activity behavior," Health Promotion Perspectives, vol. 8, no. 1, pp. 41-45, 2018.

[79] L. Huang, W. Zhao, G. Xie, H. Xie, and Q. Yi, "Evaluating and optimizing city E-commerce competitiveness based on FACA Model: a case from 32 cities in China," Revista de la Facultad de Ingenieria, vol. 32, no. 2, pp. 298-308, 2017.

[80] D. J. Cheng, Z. Song, and P. P. Wang, "Cognition trust or affect trust: how high involvement work system Affects innovation performance," Business Management Journal, vol. 032 , no. 11, pp. 81-90, 2010

[81] S. Lu and Y. Gao, "Supply chain collaboration: an analysis based on business ecosystem," Management World, no. 5, pp. 160-161, 2007.

[82] X. R. Zhang and D. Yu, "A study on the development of sharing economy in China," Journal of Xinjiang Normal University (Edition of Philosophy and Social Sciences), vol. 39, no. 2, pp. 132-146, 2018. 